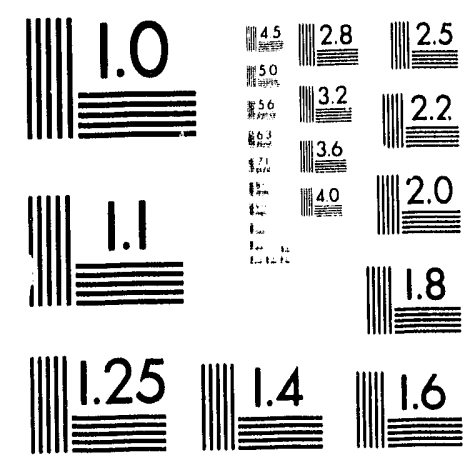



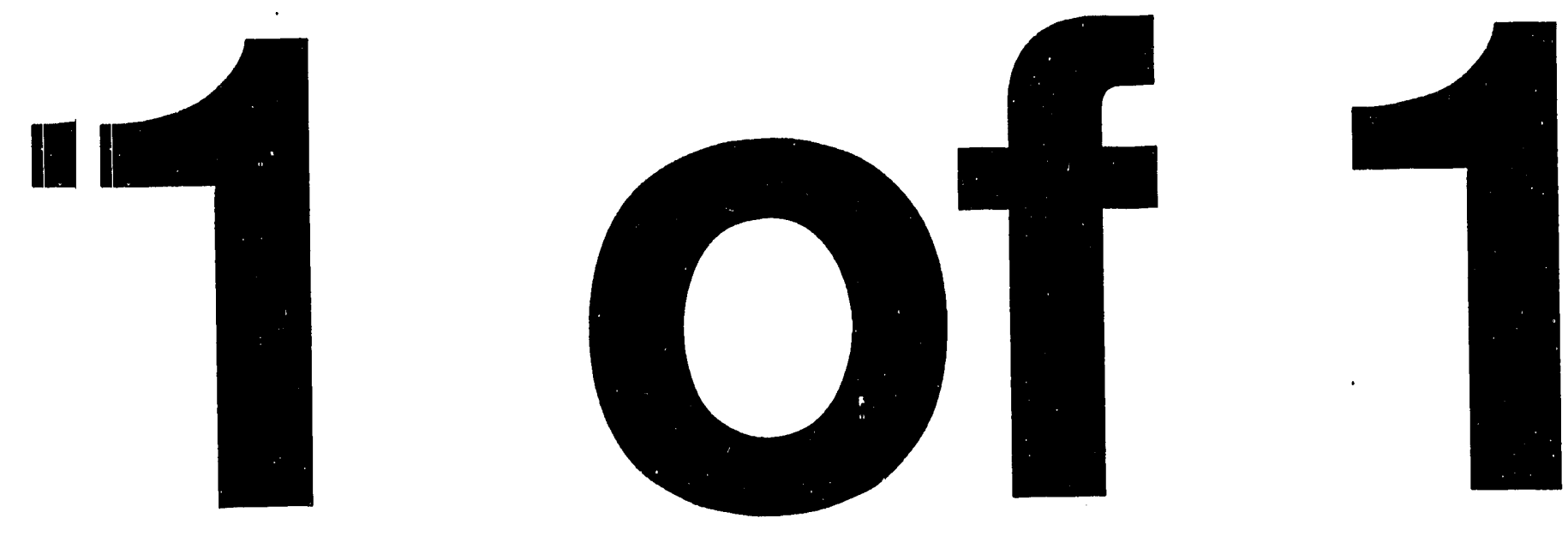
WAPD-T-3004

Page $\mathrm{I}$

ASM HANDBOOK, VOLUME 6, WELDING BRAZING, and SOLDERING

Section 19

Modeling of Joining Processes

\title{
CHARACTERIZATION AND MODELING OF THE HEAT SOURCE
}

\author{
S. S. Glickstein and E. Friedman \\ Westinghouse Electric Corp. \\ Bettis Atomic Power Laboratory \\ West Mifflin, PA
}

\begin{abstract}
A description of the input energy source is basic to any numerical modeling formulation designed to predict the outcome of the welding process. The source is fundamental and unique to each joining process. The resultant output of any numerical model will be affected by the initial description of both the magnitude and distribution of the input energy of the heat source. Thus, calculated weld shape, residual stresses, weld distortion, cooling rates, metallurgical structure, material changes due to excessive temperatures and potential weld defects are all influenced by the initial characterization of the heat source. Understandings of both the physics and the mathematical formulation of these sources are essential for describing the input energy distribution. This section provides a brief review of the physical phenomena that influence the input energy distributions and discusses several different models of heat sources that have been used in simulating arc welding, high energy density welding and resistance welding processes. Both simplified and detailed models of the heat source are discussed.
\end{abstract}




\title{
CHARACTERIZATION AND MODELING OF THE HEAT SOURCE
}

\author{
S. S. Glickstein and E. Friedman \\ Westinghouse Electric Corp. \\ Bettis Atomic Power Laboratory \\ West Mifflin, PA
}

\section{INTRODUCTION}

The heat supplied to the workpiece and then transferred within the workpiece to produce melting is at the core of any welding process. The heat transfer process or thermal cycle in the weldment has many consequences, among which are the complex metallurgical changes that take place in the fusion zone, where the metal is liquified and subsequently solidified, and in adjacent "heat-affected zone" regions where material is heated to temperatures that are below the melting point, but are sufficiently high to produce changes in the microstructure and mechanical properties. Vaporization of selective elements due to excessive temperature can also change the composition of the material. Localized heating and cooling generate plastic deformation and distributions of residual stresses that often must be reduced by postweld treatments. In addition, shrinkage of weld metal and heat-affected zone material induces permanent distortion of the weldment. Various weld defects may also be produced as a result of the thermal cycle. Some of these are porosity, hot tearing and cold cracking (Lundin). Computer modeling of welding processes to assess these phenomena is currently under development at numerous research facilities.

The description of the input energy source is basic to any numerical modeling formulation designed to predict the outcome of the welding process. Both the magnitude and distribution of the source is fundamental and unique to each joining process and the resultant output of any numerical model will be affected by the initial description of the heat source. An understanding of both the physics and the mathematical simulation of these sources is 
WAPD-T-3004

Page 2

ef essential for characterizing the heat source. This chapter provides a brief review of the

pl physical phenomena that influence the input energy distribution and discusses several

si simplified and detailed models of heat sources that have been used in modeling arc welding,

h high energy density welding and resistance welding processes.

\section{II. SIMPLIFIED MODELING OF THE HEAT SOURCE}

A Analytical modeling of the welding heat source is generally rather complex due to the nature

c of energy transfer to the workpiece, whether the source of that energy is an arc, a high

$\Theta \quad$ energy density beam of electrons or laser light, or joule heating. For numerical modeling

f purposes, heat input to the weldment is usually applied either as a distribution of surface flux,

a a distribution of heat generated internally, or a combination of both. Many analytical

$t$ treatments, however, have sought to simplify the characterization of the heat source by

a assuming the effective thermal energy supplied by the heat source to be deposited in such a

1 narrow band of material that it may be idealized mathematically as a point or a line source,

1 depending on the geometry of the weldment (Myers, et al.). Heat input idealizations of this

: sort lend themselves to the derivation of closed-form welding temperature solutions and the avoidance of developing numerical finite element or finite difference models to calculate temperatures. These solutions are strictly valid only for simple geometries and in regions removed from the fusion and heat-affected zones where details of the distribution of heat input from the source and accurate representations of the thermal energy transferred from the weld bead to the rest of the weld joint are not important.

The fundamental simplified heat source model is developed for a flat plate of infinite extent bounded by the planes $z=0$ and $z=h$. Heat is input at a point that is either stationary or is moving at uniform speed $v$, in the $x$ direction on the surface $z=0$, so that at any time $t$, the point source is located at $x=v t$ (Figure 1). Neglecting end effects resulting from initiation or 
WAPD-T.3004

Page 3

termination of the heat source or finite dimensions of the weldment, the resulting temperature distribution associated with the moving source is stationary with respect to a moving coordinate system whose origin coincides with the point of application of the heat source. This class of temperature response is termed "quasi-stationary." In general for either a stationary or a moving point source, heat is conducted through the plate without hindrance until the insulating effect of the ideally adiabatic surface at $z=h$ is felt. For a sufficiently thick plate, the temperature rise at $z=h$ is so small that the solution for an infinitely thick plate, which is associated with a single source of heat, is applicable. For a moderately thick plate, the temperature rise at $z=h$ from the infinitely thick plate point source solution is large enough to result in non-zero. heat flow at $z=h$. An image source of the same strength applied at $z=2 h$ ensures that the surface $z=h$ is adiabatic; however, the image source produces non-zero heat flow at $z=0$ and another image source applied at $z=-2 h$ is now required to satisfy conditions at $z=0$. Carrying this imposition of image point sources of heat along ad infinitum, as illustrated in Figure 2, an infinite distribution of image sources superposed with the original source at $z=0$ yields the desired adiabatic conditions at both the $z=0$ and $z=h$ surfaces. The temperature solution for this series of image sources is in the form of an infinite series (Carslaw and Jaeger), which converges more rapidly for thicker plates. The solution for the moderately thick plate applies to thin plates as well, but convergence of the infinite series would be extremely slow. As an alternative, the heat source may be applied as a line source distributed uniformly through the thickness (Rosenthal and Schmerber). This approach eliminates any variation of the temperature distribution through the thickness, and is often used to model high energy density welding processes which result in the formation of a keyhole, as.will be discussed later.

Offshoots of these cases have also been developed. These include considerations of plates of finite width, in which case sets of image sources are needed to assure adiabatic conditions 
WAPD-T-3004

Page 4

at the edges (Rosenthal, 1946), line sources of heat travelling on a circular path (Soedel and

( Cohen), and conditions that simulate initiation or termination of the heat source (Naka and

I Masubuchi). Rybicki has employed variations of the moving point source approach to

1 calculate temperatures needed for weld-induced residual stress calculations in piping.

\section{III. ARC WELDING}

A) Gas Tungsten-Arc Welding

The most frequently modeled arc welding proness is the gas tungsten-arc (GTA) process, for which the heat source is a nonconsumable electrode. In straight polarity gas tungsten-arc welding, the pieces of material are joined together by energy transferred to the workpiece mainly by four mechanisms (Schoeck):

1. Kinetic energy of the electrons comprising the arc current

2. Heat of condensation of the electrons (work function) penetrating the solid work surface

3. Radiation from the arc

4. Thermal conduction from the arc plasma to the workpiece

The first two mechanisms cc., prise the major source of energy to the weldment (Quigley, et al.).

Because of the complicated nature in which energy is transferred from the arc, heat input to the weldment may be modeled by one of the point source or line source approaches discussed in the previous section. If one of these treatments is inappropriate for the particular application, a more realistic approach is to input the energy either by a distribution of surface flux, a distribution of heat generated internally, or a combination of the two. If an 
WAPD-T-3004

Page 5

internal heat distribution is confined to a thin layer of material adjacent to the heated surface, the choice of heat input model is immaterial (Friedman and Glickstein). The magnitude of heat input to the workpiece is expressed simply as the product of what has traditionally been defined as the arc power (i.e., the product of the voltage drop across the arc and the arc current) and a factor called the arc efficiency which accounts for energy losses from the arc. Estimates of the arc efficiency can be made by correlating computed temperatures with thermocouple readings from test welds, making calorimeter measurements for a specific set of welding conditions, or utilizing some other observable response to the welding thermal cycle. Since the voltage used is usually determined from measurements at some point within the power supply, estimates need to be made to account for losses within the electrode and other parts of the system (Chihoski). Changes in welding process variables, such as shielding gas, electrode configuration, arc gap, and minor element additions to the arc, affect - the arc efficiency, as does the material that is being welded.

Although the magnitude of heat applied to the weldment surface is usually not known with great accuracy, the distribution of the heat input is even more uncertain. The distribution of the input energy depends on factors related to the electrode and the physics of the arc, as well as on the interaction of the arc with the molten weld pool. For example, the arc characteristics and the depth-to-width ratio of the weld puddle will change as the vertex angle of the conical tip of the electrode is altered as shown in Figure 3. As the arc becomes more constricted, the heat source is more concentrated, thus increasing weld penetration.

Changes in the heat source distribution (i. e., input current) will affect the electromagnetic forces in both the arc and the weld puddle resulting in changes in weld puddle motion which can promote alterations in convection heat transfer within the weld puddle. Shielding gas composition and minor alloying elements can also influence the distribution of input energy. 
WAPD-T-3004

Page 6

When welding at low currents and high voltages, the perturbation of the surface of the weld puddle may be considered to have a small effect on the heat input distribution, and a model that considers heat to be applied as a surface flux is usually satisfactory. As the current increases, however, and in particular when the arc voltage is small, indicating a short electrode-to-work surface distance, the arc jet can depress the weld puddle surface and affect the configuration of the distribution on the surface of the weldment, as shown in Figure 4. The effects of depression of the weld puddle can be accommodated empirically by postulating some or all of the heat from the arc to be deposited internally. The specification of an internal heat generation distribution, however, is more complex than that of a surface flux.

For models in which heat from the welding arc is postulated to be deposited on the surface of the weldment, the input energy is often assumed to be a radially symmetric, normally distributed surface flux at any instant of time (Pavelic, et al.). The incident heat flux q, may be expressed conveniently as an exponential, or gaussian, function such that:

$$
q(r)=\left(3 Q / m^{2}\right) \exp \left[-3(r / r)^{2}\right]
$$

where $Q$ is the magnitude of the heat input, $r$ is the distance from the center of the heat source to the surface and $r$ is a characteristic radial dimensional distribution parameter that defines the region in which 95 percent of the heat flux is deposited. In the limit as $r \rightarrow 0$, the heat input becomes a point source of strength $Q$ on the surface. The applicability of point sources to characterize energy input for laser welding processes will be explored later. Eq.(1) describes the heat input distribution from a stationary arc. Only the heat input magnitude, the distribution parameter, and the duration of heating are necessary to fully characterize the input energy. Figure 5 taken from Friedman and Glickstein shows some typical variations of the weld bead depth and the weld bead width for stationary spot welds on $6.5 \mathrm{~mm}$ thick plates with both the distribution parameter $r$, and the duration of heating $t^{\star}$. Other forms of the heat input distribution may also be used. These include ramp, or triangular, distributions, 
WAPD-T-3004

Page 7

uniform heat input distributions over finite areas (e.g., the area of the weld puddle surface), or combinations of the two (i.e., trapezoidal distributions).

The axisymmetric characterization of heat input for stationary arcs enables temperatures in the weldment to be calculated using axisymmetric thermal analysis methods if the weldment geometry justifies such an analysis. If, on the other hand, the heat source is moving, the resultant flow of heat is three-dimensional: temperature gradients develop through the thickness of the weldment as well as in directions parallel to and transverse to the welding direction. If the weldment geometry is regular (e. g., flat plate), the heat source from the arc is moving at a constant, sufficiently high speed $v$, and end effects such as the starting and stopping of the arc are neglected, transient two-dimensional thermal analyses at crosssections normal to the welding direction may be satisfactory (Friedman). The heat input at a section transverse to the direction of arc travel is given by:

$$
q(x, t)=\left(3 Q / m^{2}\right) \exp \left[-3(x / r)^{2}\right] \exp \left[-3(v t / r)^{2}\right]
$$

where $x$ is the distance from the centerline of the weld and $t$ is the time measured from the moment the center of the heat source passes over the weld section being analyzed. The three heat input parameters characterizing a moving arc $(Q, r, v)$ are embodied in this formulation. The inverse of the speed of a moving arc is akin to the duration $t^{\star}$, of a stationary arc, since a moving arc supplies a heat input $Q / v$ per unit length of weld, while a stationary arc provides a total amount of heat $Q t^{\star}$ to the weldment.

For models in which heat is deposited internally, rather than as a surface flux, the input energy may be assumed to be deposited within a spheroidal or an ellipsoidal region that is similar in shape to the weld puddle. As described by Goldak, et al., the heat input can be taken to vary exponentially as a gaussian distribution in all directions within the ellipsoid; thus the energy input distribution is completely specified by the dimensions of the ellipsoid. Yet 
n more elaborate models may be formulated by prescribing double ellipsoid heat input reglons

w which better match weld puddle shape, or conical regions of internal energy deposition.

A Regardless of the methodology chosen to characterize the distribution of the heat input, the

g geometric parameters of the distribution should, at this stage of computer modeling develop-

n ment, be established by correlating calculated thermal response characteristics, such as the

$n$ weld bead and heat-affected zone dimensions, with measured values.

\section{E B) Gas Metal-Arc Welding}

1 Modeling of the gas metal-arc (GMA) welding process is more complex than that of the GTA

f process because of the need to consider thermal energy transferred to the workpiece not

c only by the mechanisms similar to those identified for GTA welding, but more importantly by

1 heat contained in the molten metal drops transferred as filler metal from the consumable

1 electrode weld wire to the workpiece. (See, for example, Waszink and Van Den Heuval.)

Since GMA welding uses direct current reversed polarity (DCRP), the heat associated with the

I kinetic energy of the electrons and the heat of condensation (mechanisms (1) and (2) for GTA welding) is now input to the electrode. This energy previously input to the weldment is replaced by the energy of positively charged ions which contribute a much smaller amount of heat to the weldment. In addition, the radiation and conduction via the arc plasma make minor contributions to the heat input to the weldment. The more important source of heat is from the mass of molten material and is related directly to both the temperature and the melting rate of the weld wire. The melting rate of the electrode is governed primarily by joule heating and "arc heat" similar to GTA welding. Transfer of material to the workpiece can be globular, such that the metal is deposited in distinct drops, or spray, in which mass is transferred to the weld puddle as fine droplets. 
WAPD-T.3004

Page 9

The thermal energy applied to the workpiece consists, therefore, of two sources: the "arc energy" distribution generated at the cathode area (workpiece), and the thermal energy of the metal drops transferred from the filler wire. The arc input energy has a significant effect on the width of the weld puddle, and thus of the solidified weld bead, while the energy in the molten metal contributes strongly to the melting of the workpiece (Essers and Walter). The impingement of the metal drops on the puddle, furthermore, greatly affects the depth of penetration (Tsao and Wu); this is due to the impact of each drop causing a distinct indentation in the weld puddle, especially at high currents.

Modeling of the heat input from GMA welding should generally include the effects of heat input from the filler metal droplets, the addition of new weld material from the filler wire and, in many cases, significant indentation of the weld puddle surface, as well as a spatially distributed heat flux on the surface to represent radiation energy from the arc and positive ion impingement. Accurate representations of these phenomena are so complex that alternate treatments are essential. Tekriwal and Mazumder modeled heat input from iMA welding as a gaussian distribution accounting for the energy necessary to melt the weld wire, while Josefson developed a model in which heat is input partly in the weld puddle and partly as a surface flux. A more common approach is to model the addition of filler metal by "creating" new metal in an analytical model. In finite element treatments, for example, new metal is simulated by adding sets of elements to the model. For three-dimensional models, these elements may be introduced in distinct increments of time, while for a two-dimensional analysis of a cross-section normal to the welding direction, a set of elements corresponding to a weld bead cross-section may be created. More recently, the contour outlining the weld bead has been determined experimentally and then used as the starting boundary condition for thermal modeling of welds. As an example, the boundary condition can be a time dependent temperature that may reach or exceed the melting temperature of the material. 
WAPD.T.3004

Page 10

\section{Other Arc Welding Processes}

Shielded metal-arc welding (SMAW), submerged arc welding (SAW), and flux cored arc welding (FCAW) are other welding processes for which energy is transterred to the workplece both from the arc and from an overheated consumable electrode. Although the introduction of a slag layer, whether it develops from the melting and solldification of material from an electrode covering or from a flux feeding tube, presents another factor to be accounted for in the calculation of weld-induced temperatures, the semiempirical methodology outlined for simulating the heat input for the GMAW process appears to be well sulted for the flux welding processes as well.

\section{HIGH ENERGY DENSITY WELDING}

In modeling the heat source for high energy density (HED) welding, one needs to determine first the type of weld process being formulated. Depending on the weld parameters, the HED process may simulate a conduction mode weld process or a keyhole weld process. If a strict conduction mode weld process is being modeled. the energy density is low enough that intense vaporization of the material does not occur. All the energy of the beam is deposited directly on the surface of the weldment as a heat flux similar to that discussed previously for the gas tungsten-arc welding process. The major difference between this mode of welding and that of arc welding is in the magnitude and distribution of the heat source. In laser welding, the input energy distribution is very dependent upon the operational mode of the laser system. Figure 6 shows several shapes of the source distribution that may be present at any one time. The fundamental transverse electromagnetic mode, TEM oo (a gaussian distribution) is often selected as the heat input description for conduction welding. It is also assumed as the source distribution for electron beam welding. The exact determination of 
WAPD-T-3004

Page 11

The gaussian width parameter i depends on the optlcs of the laser or electron beam welding syatem. In many cases, a point source on the surface is an excellent approximation. In laser walding, If the energy is delivered via a flber optlc delivery system, the output source distribullon has often been described as a truncated gaussian source distribution of specified width. However, Liu \& Leong (1992), have examined the beam exiting a fiber optic system and reported that the output energy distribution depends on the incident angle of the beam into the llber. A variety of output conflgurations can be obtained as a function of the angle.

Some laser systems such as the AVCO multikilowatt $\mathrm{CO}_{2}$ laser operate with the TEM $\mathrm{T}_{0}$ as the dominant mode. This donut shape shown in Figure 6 has been used very effectively for specilic welding operations. Other laser systems may display a combination of these modes (e.g. TEM $\mathrm{M}_{02}$ ) as well as higher order modes. Beam analyzers are currently being employed to measure the precise distribution of the laser input energy to the weldment.

If a keyhole mode of welding is being formulated, modeling of the input heat distribution is complicated and several different formulations have been discussed in the literature. In the keyhole mode the energy density is sufficiently high to cause material ablation near the center of the beam, resulting in penetration of the beam further into the weldment. A hole created in the material is maintained by equilibrium between vapor pressure in the keyhole, surface tension and hydrodynamic pressure in the surrounding melt. The exact distribution of energy deposited in the hole is complicated and depends on the scattering and absorption ol the beam through the weldment, as well as on the focal parameters of the system.

Several different models have been used to simulate these conditions.

For the keyhole mode of welding, the simplest model is that of a moving line source through the woldment (Swift-Hook \& Gick). The appropriate solution of the heat equation was 
WAPD-T-3004

Page 12

obtained by Rosenthal (1941). The model does not describe the typically observed semicircular part of the weld at the top, since it corresponds to a liquid region whose size does not vary through the thickness of the workpiece. This simple model has been found to be very useful, however, providing relations between such quantities as the power absorbed and the width of the weld.

To obtain a more realistic weld shape, Steen, et al. modified the simple line source approach by adding a point source close to the surface of the workpiece, to the line source distributed uniformly through the thickness. The line source models uniform absorption of heat by the workpiece with depth, while the point source corresponds to a much more concentrated region of absorption in the vicinity of the laser focus, which contrasts with the absorption from multiple reflections that occur in the main part of the keyhole. The temperature distribution from this combined source model yields a vertical weld seam shape that reflects the general shape of that found from experimental investigations as shown in Figure 7 (Steen).

A simple description of the input energy avoids the problem of defining the exact nature of the energy-transfer process in the keyhole itself. A more sophisticated model is necessary to characterize this effect. Mazumder and Steen have considered attenuation of the laser beam in the vertical direction by calculating the temperature at a depth $d$ below the surface. If the temperature at depth $d$ exceeds the boiling point of the material, the point $d$ is deemed to be transparent and the incident power is then applied at a point below it after suffering some absorption. This sequence continues through the substrate. The transparent grid points keep their high temperatures as if the keyhole were filled with a hot plasma.

This brief overview of several approaches used to model the HED welding process points out the difficulty in defining a unique methodology. Experimental data must be used for specific 
welding conditions to establish both the overall approach as well as the magnitude and distribution of the input source energy.

\section{RESISTANCE WELDING}

The electrical resistance spot welding process for joining two materials at their common interface is a complicated interaction of electrical, thermal, mechanical, metallurgical and surface phenomena. Figure 8 is a simplified representation of the process, showing some of the essential features for producing a weld. In this welding process, the faying surfaces of two or more workpieces are fused and joined at a spot by joule heating (electric current flowing through the weldment). The weldment is actually held together by the compressive force exerted by the electrodes. Because the input energy in this weld process is due to joule heat, in modeling the heat source, the spatial distribution of the current and the electrical resistance within the workpiece must be determined. Most importantly, the contact resistance at the surfaces of both the electrode and the workpiece and the interfaces of the workpieces must be established. The electrical contact resistance depends upon the surface condition of the material, its hardness, the degree of oxidation, the amount and kind of impurities, as well as the apparent pressure at the surfaces and the temperature. The fact that these quantities are time dependent provides further complication since the joule heat source must be considered as a time dependent parameter.

A detailed description of the process is presented in the ASM Handbook. Literature reviews of the resistance spot welding process simulation can be found in articles by Nied and Tsai. A brief overview of some important findings in the literature on resistance welding helps to highlight several points that need to be considered in developing a model of the heat source. 
WAPD-T.3004

Page 14

In 1958 Greenwood and Williamson performed experimental and analytical investigations of the resistance spot welding process. They reported current density singularities at the outer rim of the contact area from theory and correlated this phenomenon with experimental results which showed heat concentration at the periphery. They concluded that the bulk of the material near the contact region is not heated appreciably by the flow of current through it, but is heated indirectly by conduction from the peripheral region of the contact area. However, further study indicated that the contact area plays a major role only in the early stages of heat production and becomes less influential in later stages of the weld nugget formation. This fact reinforces the earlier remarks that the modeling of the heat source must take into consideration not only the spatial distribution of the heat source but its time dependence. To further reinforce this idea, Cho and Cho have found that in the beginning of the welding process most of the voltage drop takes place at the interface between the electrode and the weldment and in the interface of the two workpieces $(21 \%$ and $66 \%$, respectively). They determined that after six cycles from the instant that fusion of the weldment begins, most of the voltage drop takes place in the base metal $(87 \%)$. This occurs because (1) the interfacial resistance decreases as the temperature rises due to melting at the interface, and (2) the resistivity of the base metal increases with increased temperature.

Complicating the modeling process is the unknown, but very important contact diameter at the faying surface. This parameter depends upon the geometry of the electrodes, the surface conditions and, most importantly, the mechanical load applied by the electrode. Recent work by Tsai, et al. in modeling this process uses the diarneter of the electrode face as the contact diameter between the electrode and workpiece, but a slightly larger diameter to represent the contact diameter at the interface of the workpieces. Figures 9 and 10 taken from Nied's work show the current density and joule heating as functions of the nondimensional radius $R / R_{c}$ where $R_{c}$ is the assumed contact radius. 
WAPD-T-3004

Page 15

Both Nied and Tsai stress the importance of developing a thermomechanical coupling model that will account for changes in resistance and current distributions during the weld process.

This discussion has tried to point out that the input description of the heat source for resistance welding is extremely complicated. It depends upon the electrode geometry, the weldment material, and the weldment surface condition, as well as the weld parameters (which include the mechanical forces on the electrode) that must be considered as time dependent. 


\section{V| VI. SUMMARY}

A A description of the input energy source is basic to any numerical modeling formulation

di designed to predict the outcome of the welding process. The source is fundamental and

ul unique to each joining process. The resultant output of any numerical model will be affected

b by the initial description of both the magnitude and distribution of the input energy of the heat

si source. Thus, weld shape, residual stresses, weld distortion, cooling rates, metallurgical

st structure, material changes due to excessive temperatures and potential weld defects are all

ir influenced by the initial characterization of the heat source. Understandings of both the

$p$ physics and the mathematical formulation of these sources are essential for describing the

ir input energy distribution. This section has provided a brief review of the physical phenomena

tt that influence the input energy distributions and has detailed several different models of heat

s sources that have been. used in simulating arc welding, high energy density welding and

r resistance welding processes. Although considerable progress has been achieved in recent

$y \quad$ years in understanding the basic physics of welding processes and in constructing complex

c computer models to describe them, experimental data remains necessary at the present

s stage of development to properly determine the input parameters characterizing the heat

s source. 


\section{REFERENCES}

ASM Handbook Vol. 6, Welding, Brazing, and Soldering, 9th Ed.

Carslaw, H. S. and Jaeger, J. C., Conduction of Heat in Solids, Oxford, Clarendon Press, London, 1959.

Chihoski, R. A. "The Rationing of Power Between The Gas Tungsten Arc and Electrode," Weld. J. Res Suppl., 49 (2) Feb. 1970, pp. 69s-82s

Cho, H. S., and Cho, Y. J., "A Study of the Thermal Behavior in Resistance Spot Welding," Weld J. Res. Suppl., June 1989 pp. 236s-244-s

Cline, H. E. and Anthony, T. R., "Heat Treating \& Melting Material With a Scanning Laser or Electron Beam," J of Appl. Phys. 48 (9), 1977, p. 3895

Essers, W. G. and Walter, R., "Heat Transfer and Penetration Mechanisms With GMA and Plasma-GMA Welding," Weld. J. Res. Suppl., Vol. 60, February 1981, pp. 37s-42s.

Friedman, E., "Thermomechanical Analysis of the Welding Process Using the Finite Element Method," ASME Trans. J. Press. Vess. Techn., Vol. 97, August 1975, pp. 206-213.

Friedman, E. and Glickstein, S. S., "An Investigation of the Thermal Response of Stationary Gas Tungsten-Arc Welds," Weld. J. Res. Suppl., Vol. 55, No. 12, December 1976, pp. 408s-420s. 
WAPD-T-3004

Page 18

Goldak, J., et al., "Computer Modeling of Heat Flow in Welds," Metallurgical Trans. B, Vol. 17B, September 1986, pp. 587-600.

Key, J. F., "Anode/Cathode Geometry and Shielding Gas Interrelationships in GTAW," Weld. J. Res. Suppl., Dec. 1980 p. 364-s

Greenwood, J. A. and Williamson, J. B. P., Electrical Conduction in Solids-Il. Theory of Temperature-Dependent Conductors, Proc. Royal Soc. of London, 246:13-31, 1958

Josefson, B. L., "Residual Stresses and Their Redistribution During Annealing of a Girth-Butt Welded Thin-Walled Pipe," ASME Trans. J. Press. Vess. Techn., Vol. 104, August 1982, pp. $245-250$.

Liu, Y. and Leong, K. H., "Laser Beam Diagnostics for Kilowatt Power Pulsed YAG Laser," Proceedings of Laser Materials Processing, ICALEO'92, LIA Vol. 72, 1992

Lundin, C. D., "The Significance of Weld Discontinuities - A Review of Current Literature," Welding Research Council Bulletin No. 222, December 1976.

Mazumder, J. and Steen, W. M., "Heat Transfer Model for CW Laser Material Processing," J.Appl. Phys. 51 (2) 1980, p. 941

Myers, P. S., Uyehara, O. A. and Borman, G. L., "Fundamentals of Heat Flow in Welding," Welding Besearch Council Bulletin No. 123, July 1967 
Naka, T. and Masubuchi, K., "Temperature Distribution of Welded Plates," J. Japan Welding Soc., Vol. 16, Nos. 7 and 12, 1947, Part I pp. 281-290, Part II pp. 374-378.

Nied, H. A., "The Finite Element Modeling of the Resistance Spot Welding Process," Weld. J. Res. Suppl., April 1984 p. 123-s

Pavelic, V., Tanbakuchi, R., Uyehara, O. A. and Myers, P. S., "Experimental and Computed Temperature Histories in Gas Tungsten-Arc Welding of Thin Plates," Weld. J. Res. Suppl., Vol. 48 , No. 7, 1969, pp. 295s-305s.

Quigley, M. B. C., Richards, P. H., Swift-Hook D. T. and Gick, A. E. F., "Heat Flow To The Workpiece From A TIG Welding Arc," J. Phys. D. Appl. Phys., Vol. 6, Dec 1973, pp. $2250-2259$

Rosenthal D., "Mathematical Theory of Heat Distribution During Welding and Cutting," 1941 Welding J. Res. Suppl, Vol. 20 pp. 220s-234s

Rosenthal, D., "The Theory of Moving Sources of Heat and Its Application to Metal Treatments," Trans. ASME, Vol. 68, 1946, pp. 849-866.

Rosenthal, D. and Schmerber, R., "Thermal Study of Arc Welding," Weld. J. Res. Suppl., Vol. 17, No. 4, 1938, pp. 2s-8s.

Rybickl, E. F., et al., "A Finite-Element Model for Residual Stresses and Deflections in GirthButt Welded Pipes," ASME Trans, J. Press. Vess. Techn., Vol. 100, August 1978, pp. 256-262. 
WAPD-T-3004

Page 20

Schoeck, P. A., "An Investigation of the Anode Energy Balance of High Intensity Arcs in Argon," Modern Developments in Heat Transfer, Academic Press, New York, 1963, pp. $353-400$.

Soedel, W. and Cohen, R., "Arc-Welding Temperatures in a Circular Disk Structure," Weld. J. Res. Suppl., Vol. 49, No. 7, 1970, pp. 337s-340s.

Steen, W. M., Dowden, J., Davis, M., and Kapadia, P., "A Point and Line Source Model of Laser Keyhole Welding," J.Physics D: Appl Phys. 21 (1988) pp. 1255-1260,

Switt-Hook, D. T. \& Gick, A. E. F., "Penetration Welding with lasers-Analytical Study Indicates that Present Laser Beam Welding Capabilities May Be Extended Tenfold," Weld. J. Res. Suppl. Vol. 52, pp. 492s-499s (1973).

Tekriwal, P. and Mazumder, J., "Finite Element Analysis of Three-Dimensional Transient Heat Transfer in GMA Welding," Weld. J. Res. Suppl., Vol. 67, No. 7, 1988, pp. 150s-156s.

Tsal. C. L., Jammal, O. A. , Papritan, J. C. and Dickinson, D. W., "Modeling of Resistance Spot Weld Nugget Growth," Weld J. Res. Suppl. Feb. 1992, p. 47-s

Tsao, K. C. and Wu, C. S., "Fluid Flow and Heat Transfer in GMA Weld Pools," Weld. J. Res. Suppl, Vol. 67, March 1988, pp. 70s-75s.

Waszink, J. H. and G. J. P. M. Van Den Heuval, "Heat Generation and Heat Flow in the Filler Metal in GMA Welding," Weld. J. Res. Suppl., Vol. 61, August 1982, pp. 269s-282s. 


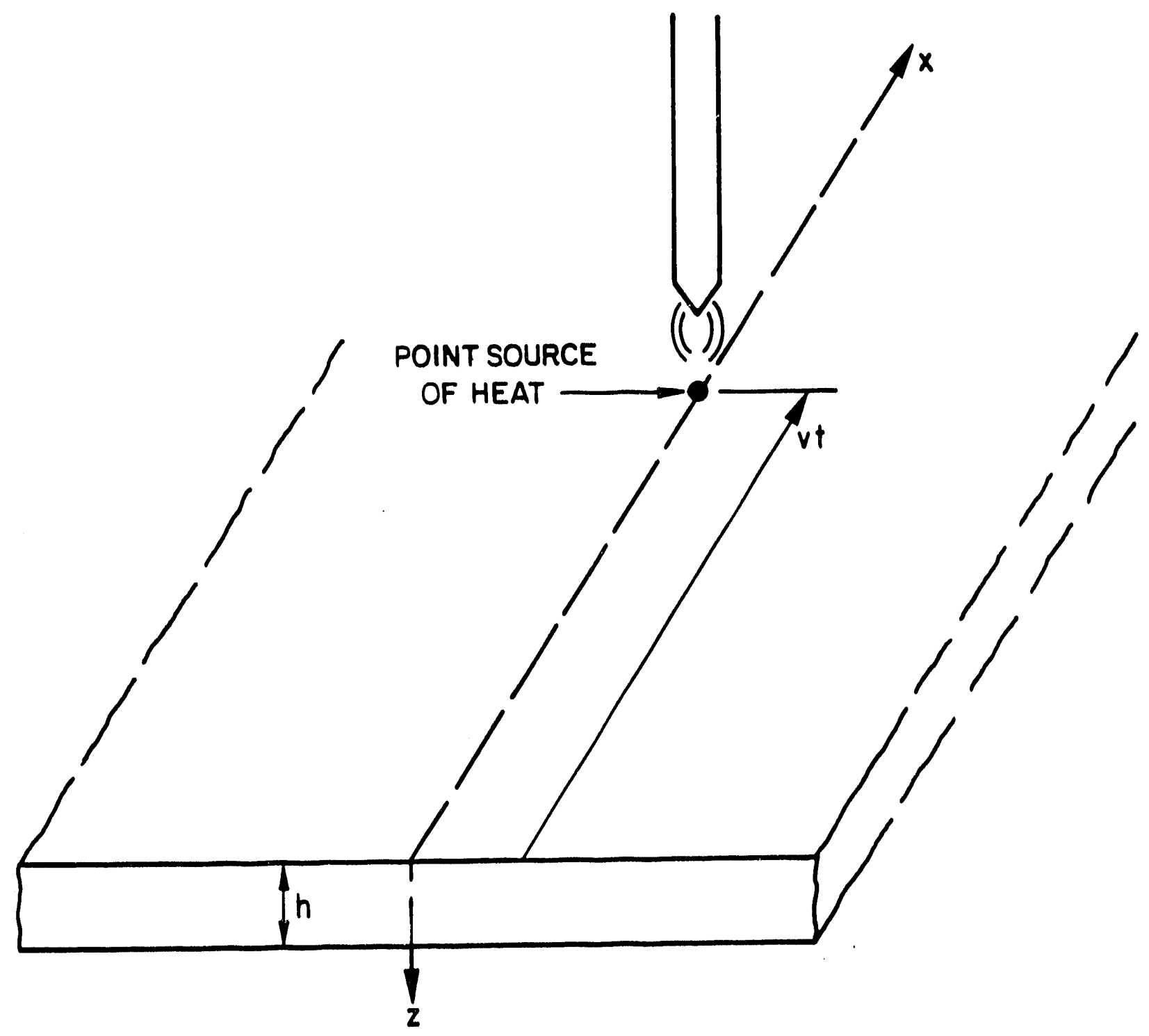

FIGURE I. MOVING POINT SOURCE IN INFINITE PLATE 
WAPD-T-3004

Page 22

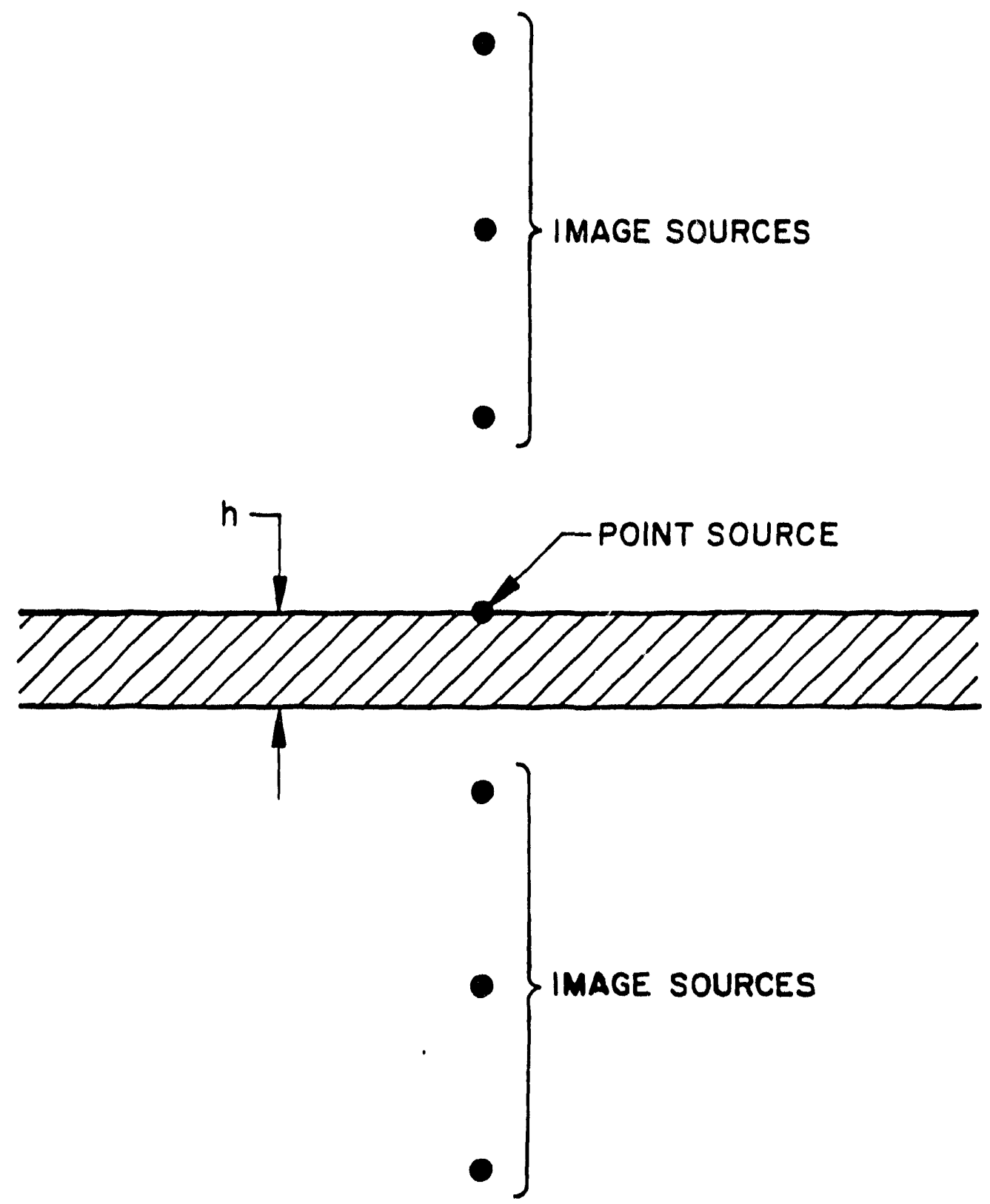

FIGURE 2. SUPERPOSITION OF IMAGE SOURCES IN FINITE THICKNESS PLATE 


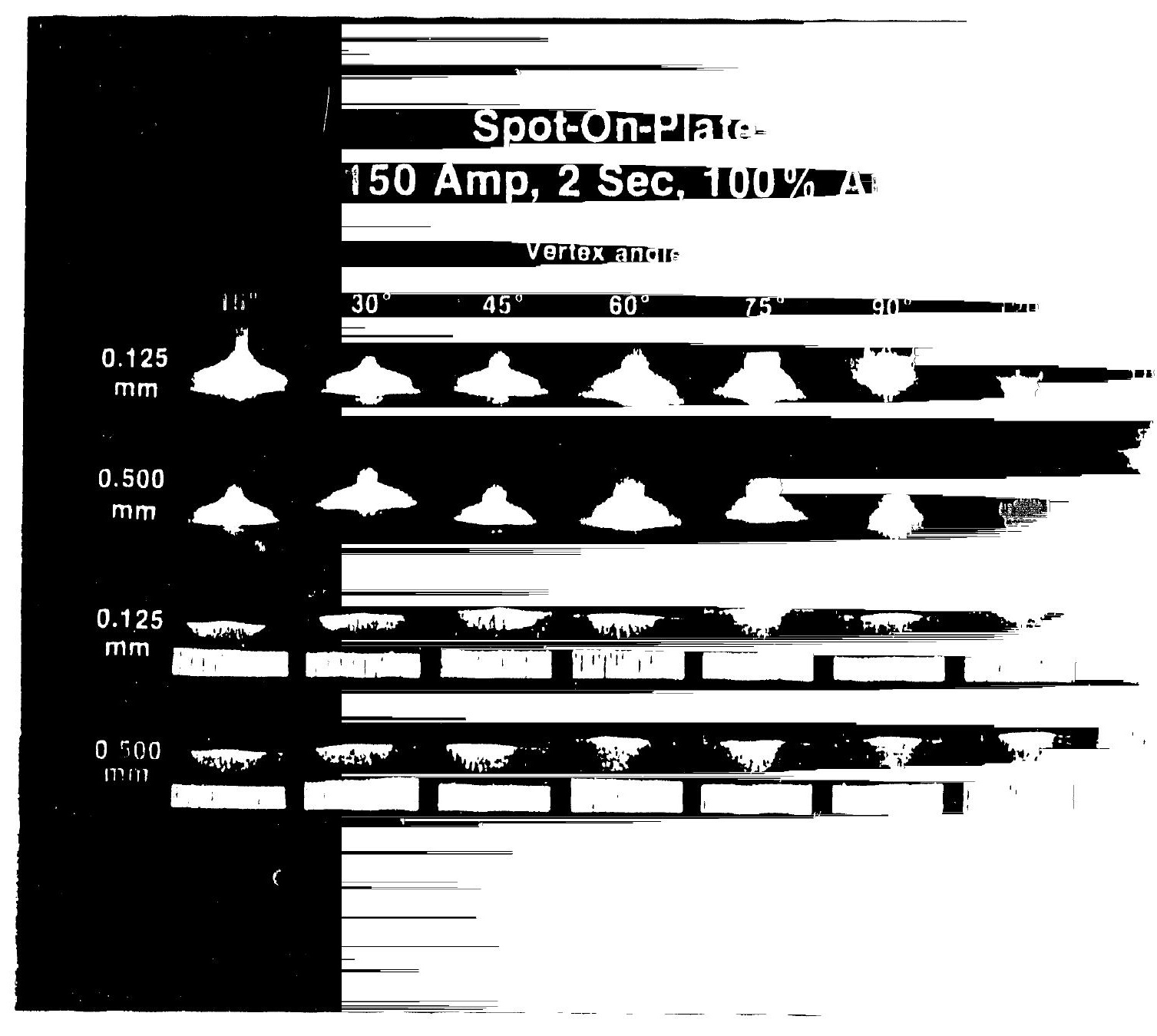

FIGURE 3. ARC SHAPE AND WELD BEAD GEOMETRY AS A FUNCTIO OF ELECTRODE TIP ANGLE IN A PURE ARGON SHIELD F 2.38mm DIAMETER ELECTRODES TRUNCATED TO $0.125 \mathrm{~m}$ AND $0.500 \mathrm{~mm}$, ARC GAP $\therefore 1 \mathrm{~mm}$ (KEY) 
WAPD.T.3004

Page 24

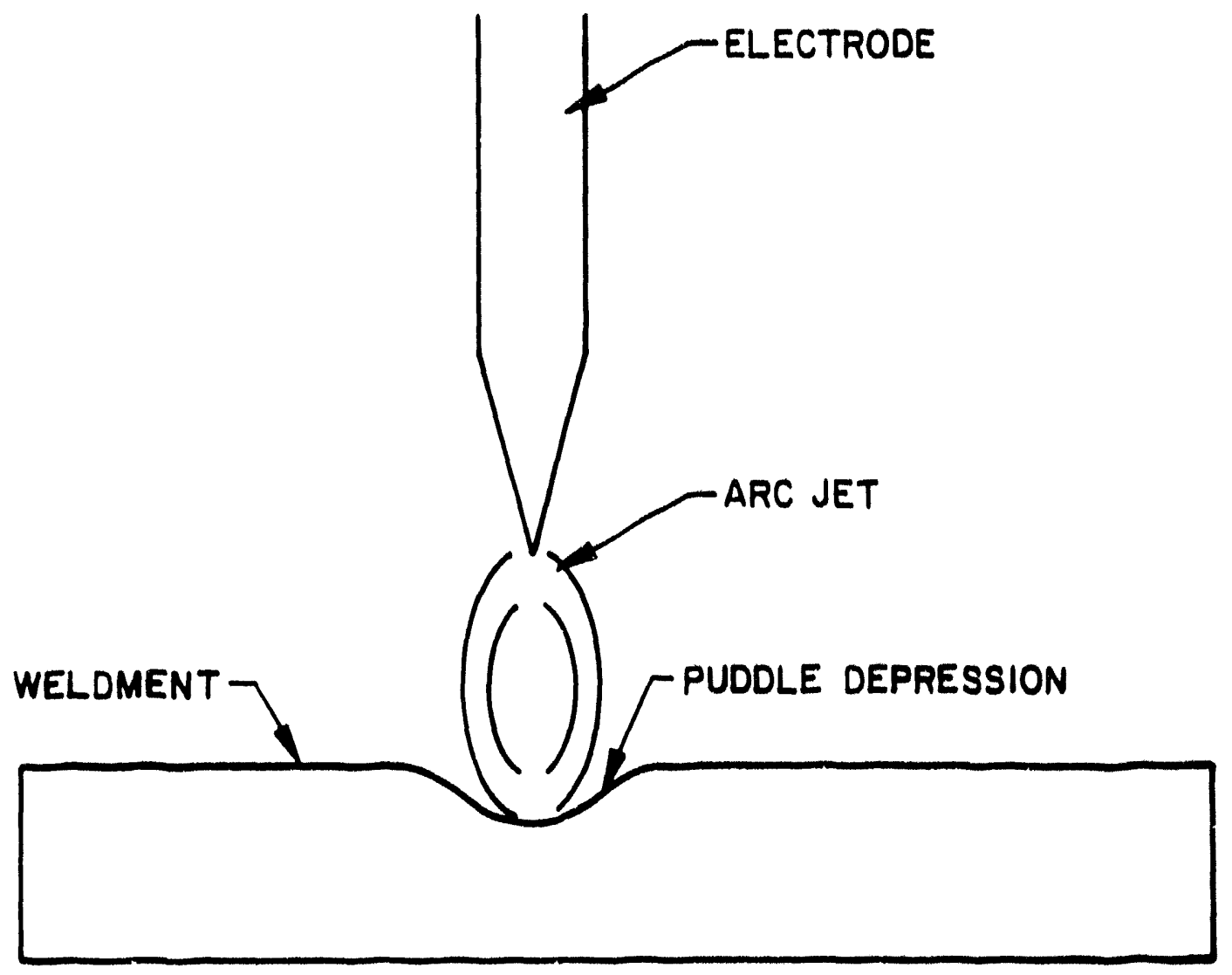

FIGURE 4. EFFECT ARC JET ON DEPRESSION OF WELD POOL 

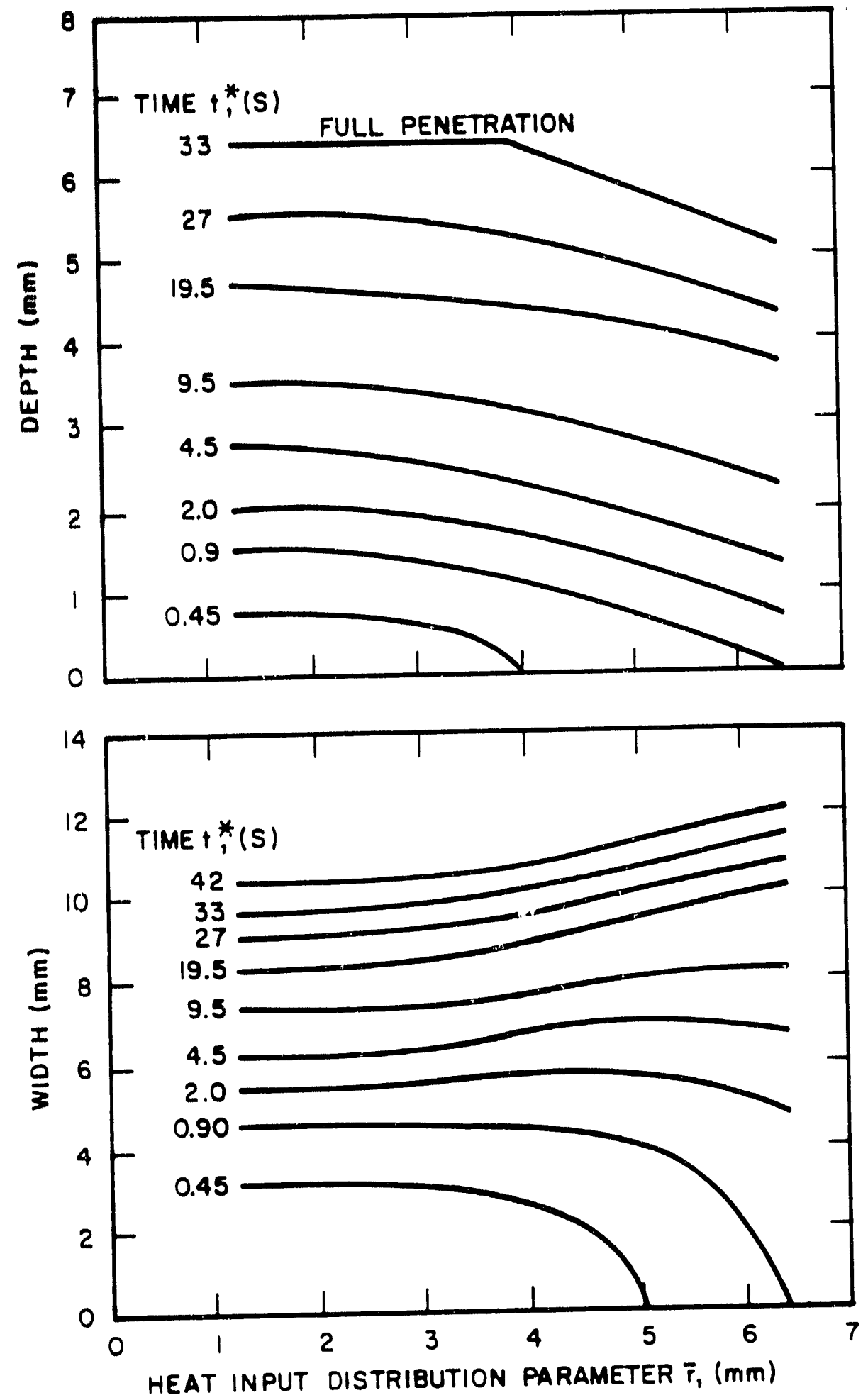

FIGURE 5. WELD BEAD DIMENSIONS FOR DIFFERENT DURATIONS OF HEATING ${ }^{*}$, AND HEAT INPUT DISTRIBUTION PARAMETERS $\bar{r}$. $Q_{0}=1060 \mathrm{~W}$ (FRIEDMAN AND GLICKSTEIN) 
$n$
$w$
0
0
$\sum$
$上$
$⺊$
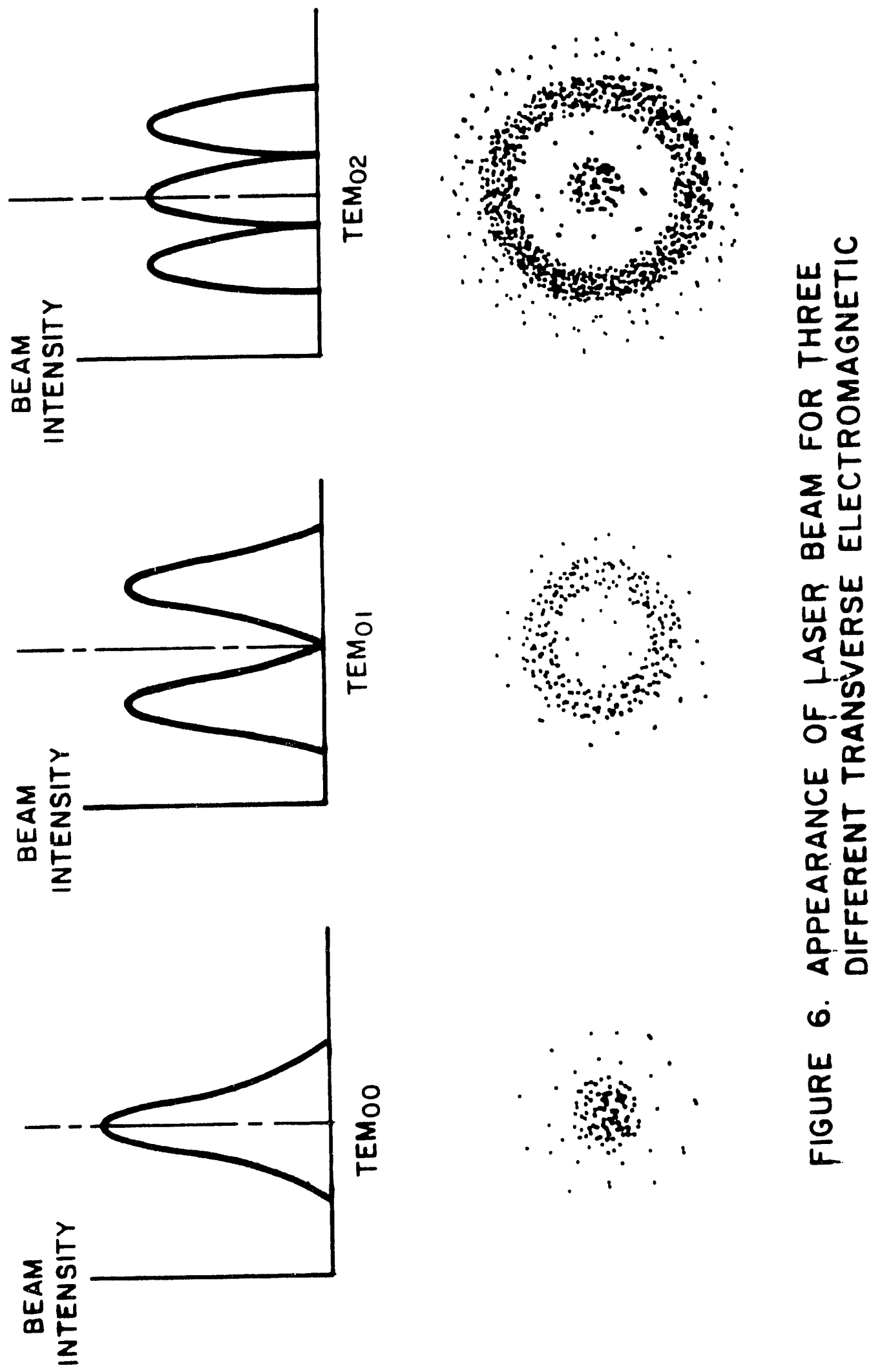

$\propto \omega$

电

4

$\perp$ o

능 z

u正

统卢

o. $\frac{\omega}{\alpha}$ (s)

4 w w

u

는응

승

$\dot{0}$

$\underset{\frac{\omega}{\alpha}}{\frac{w}{2}}$ 

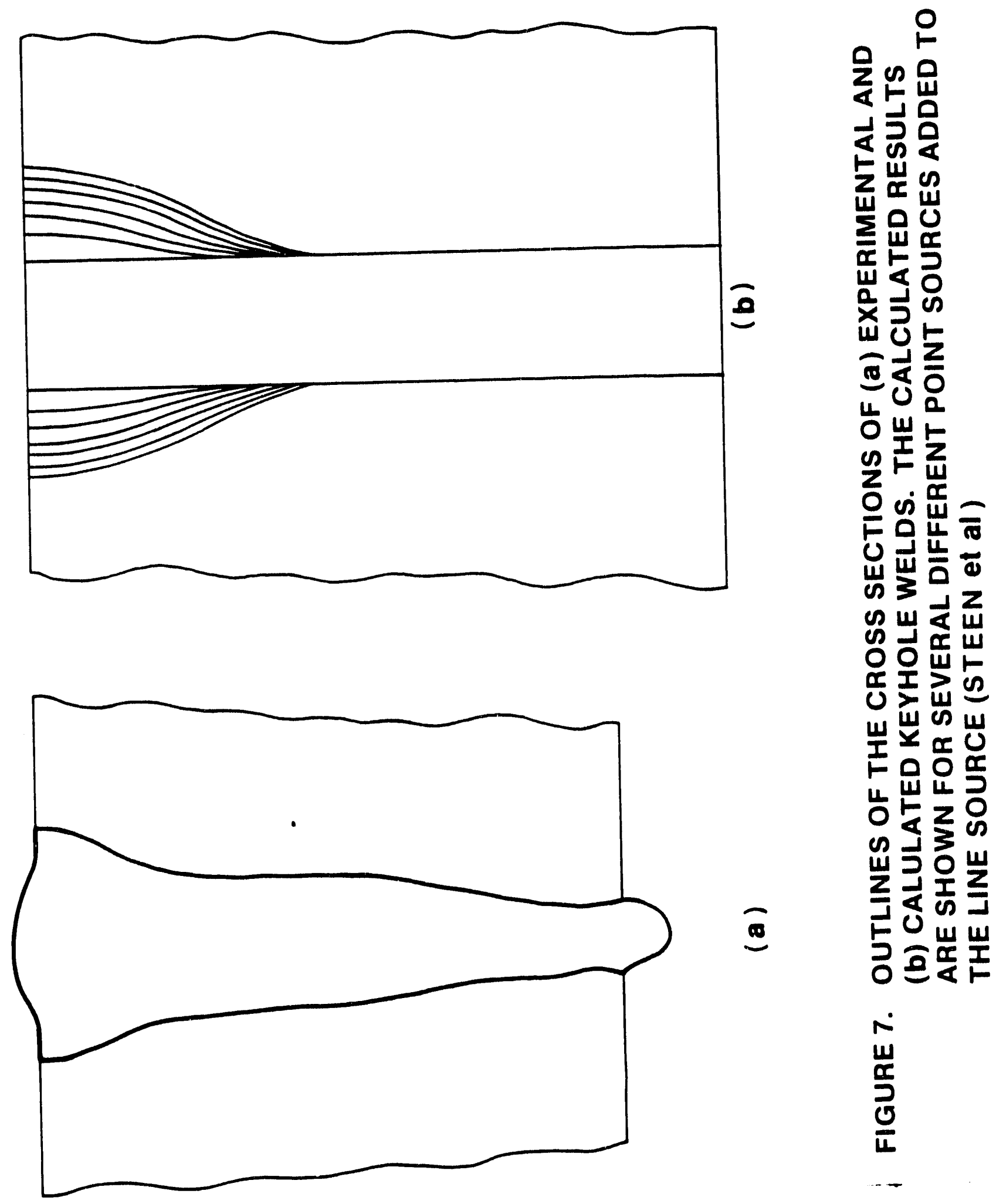


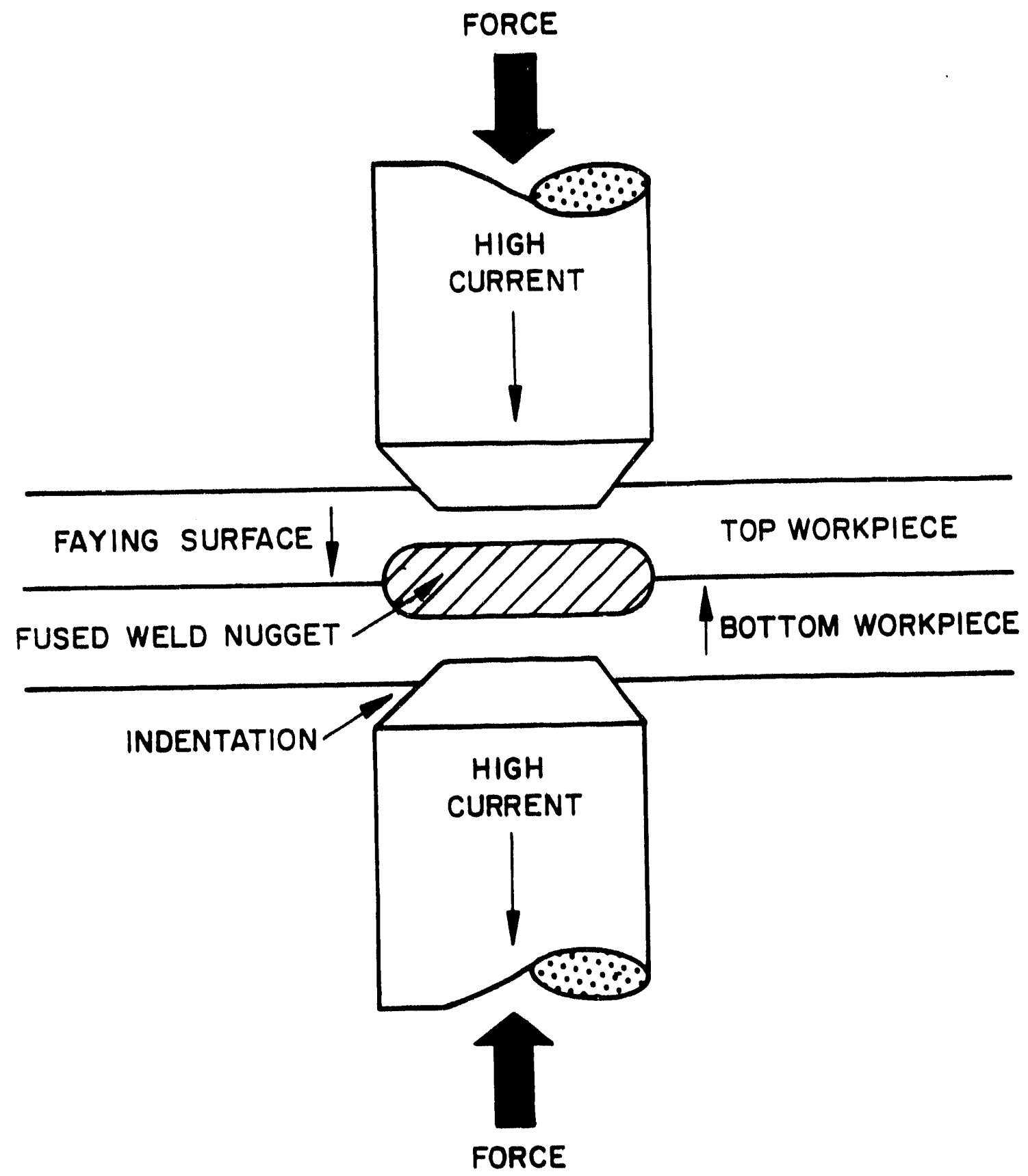

FIGURE 8. RESISTANCE SPOT WELDING PROCESS 


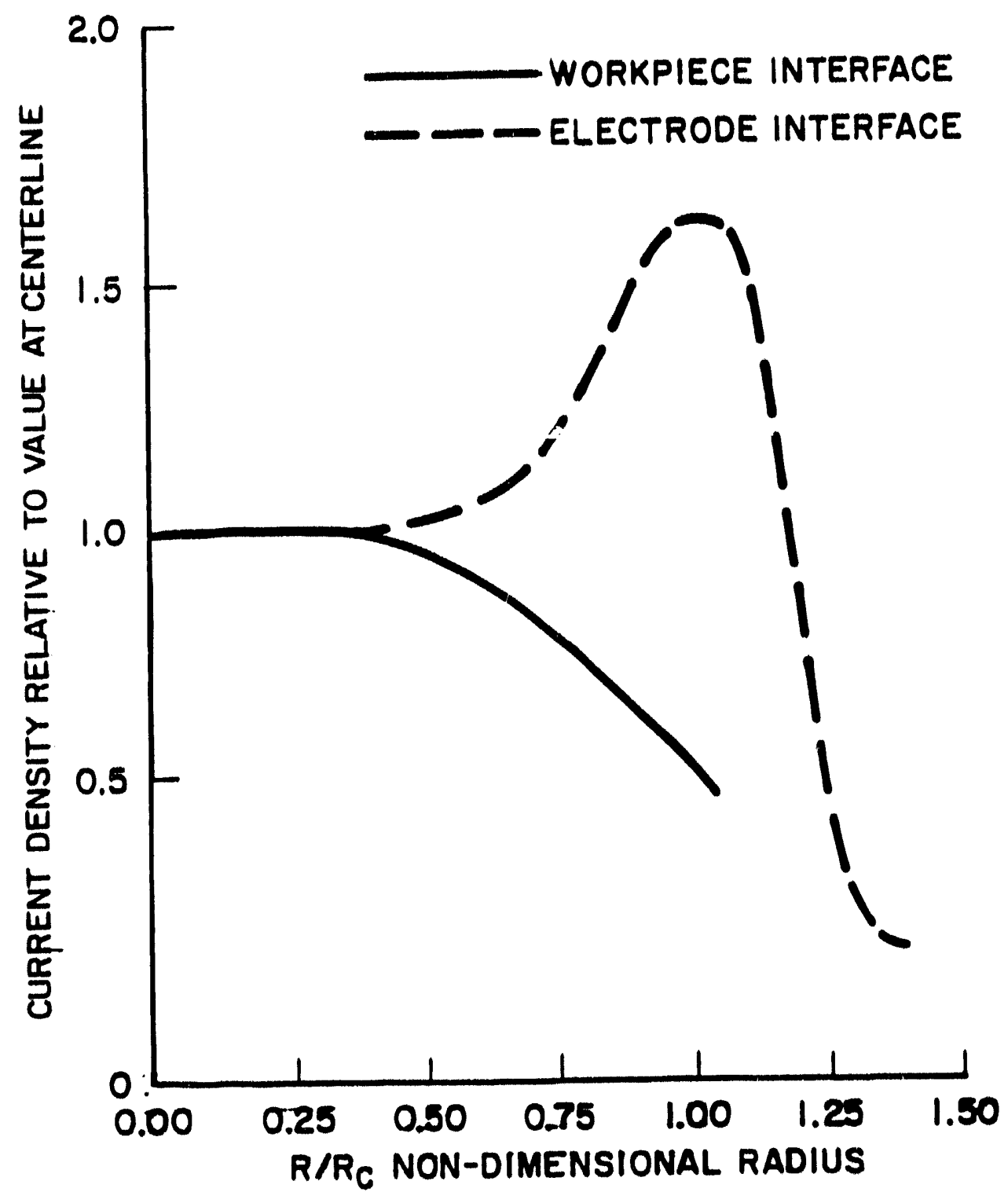

FIGURE 9. CURRENT DENSITY RATIO VS NON DIMENSIONAL RADIUS; TIME $=2$ CYCLES, $R_{\dot{C}}=$ RADIUS OF CONTACT (NIED) 


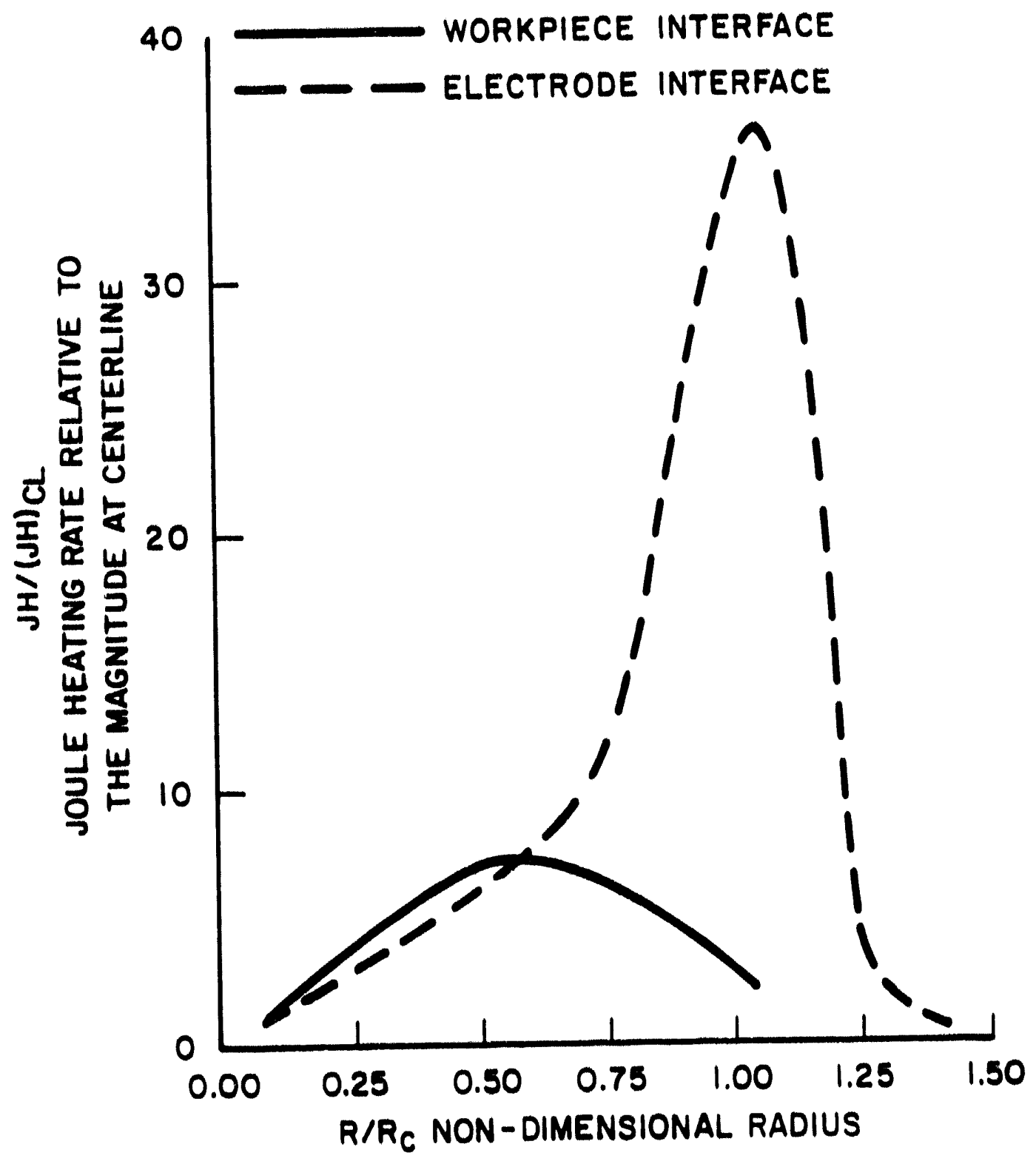

FIGURE 10. JOULE HEATING RATE RATIO VS NONDIMENSIONAL RADIUS; TIME $=2$ CYCLES, $R_{C}=$ RADIUS OF CONTACT (NIED) 

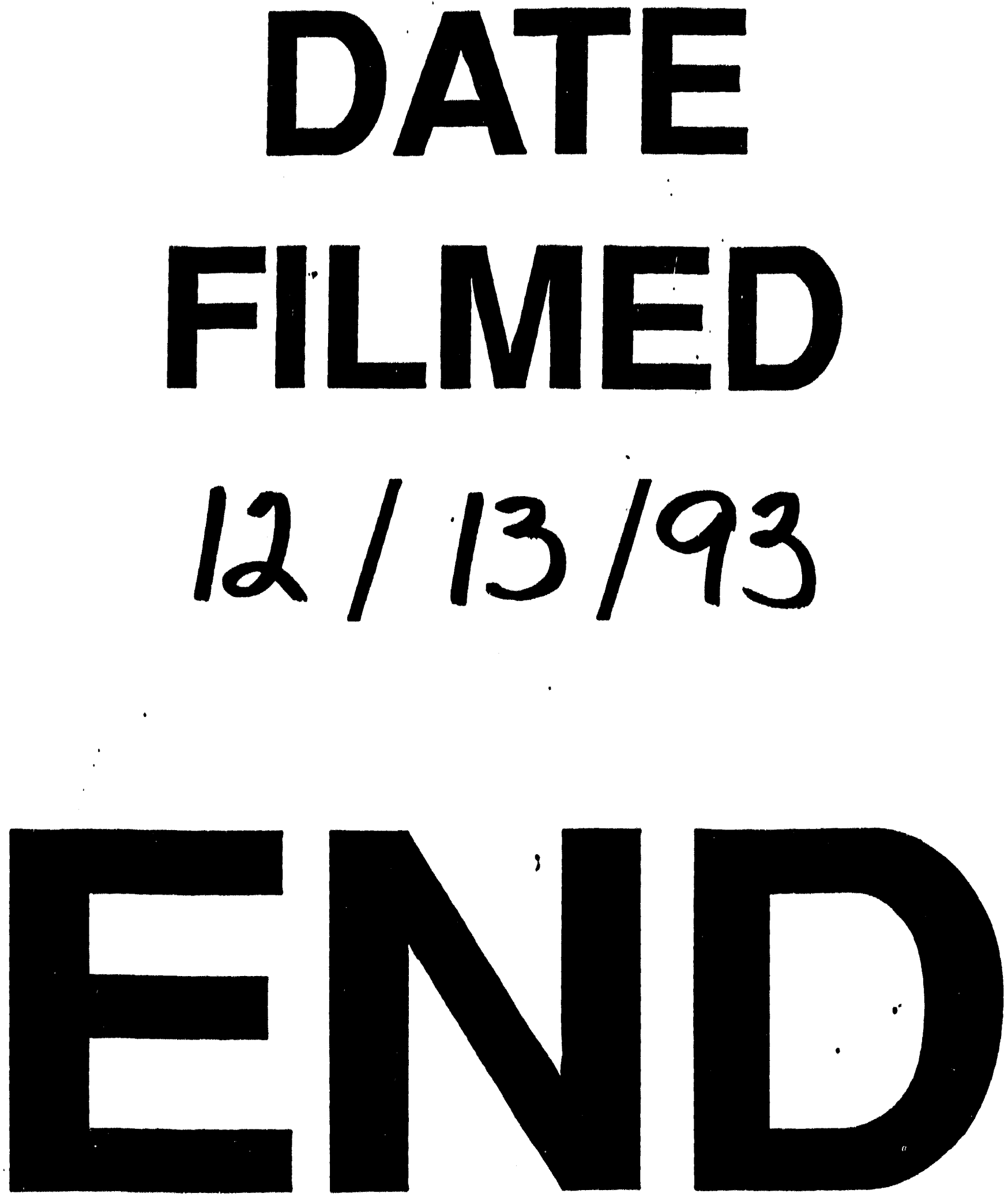
